\title{
QUALIDADE FISIOLÓGICA E PRODUÇÃO DE MUCILAGEM EM SEMENTES DE ESPÉCIES DA SUBTRIBO HYPTIDINAE (LAMIACEAE) COLETADAS EM DIFERENTES ESTÁDIOS DE MATURAÇÃO
}

\author{
$\underline{\text { Samuel Pereira da Silva }}{ }^{1}$; Lenaldo Muniz de Oliveira ${ }^{2}$; Rafael Cruz Cordeiro $^{3}$ e \\ Marcelo Magalhaes Costa ${ }^{4}$. \\ 1. Bolsista IC/FAPESB, Graduando em Agronomia, Universidade Estadual de Feira de Santana, e-mail: \\ samuell@doctor.com. \\ 2. Orientador, Departamento de Ciências Biológicas, Universidade Estadual de Feira de Santana, e-mail: \\ lealdo.uefs@gmail.com \\ 3. Bolsista IC/FAPESB, Graduando em Agronomia, Departamento de Nome, Universidade Estadual de Feira de Santana, e- \\ mail: rcccordeiro12@gmail.com \\ 4. Graduando em Agronomia, Universidade Estadual de Feira de Santana, e-mail: marcelomagalhaes80@ otmail.com
}

PALAVRAS-CHAVE: Germinação; Fenologia, Plantas medicinais nativas, Lamiaceae.

\section{INTRODUÇÃO}

A caatinga, bioma predominante da região do semiárido, ocupa uma área equivalente a 11\% do território nacional (MMA, 2017). Possuindo uma grande biodiversidade, a caatinga é caracterizada como floresta arbórea ou arbustiva. Muitas espécies possuem elevado interesse pelo seu potencial econômico para uso na indústria alimentícia e farmacêutica.

Fazendo parte desse bioma temos a família Lamiaceae, detentoras de inúmeras espécies medicinais e aromáticas, muito utilizadas na culinária e na medicina tradicional. As espécies nativas dessa família são pouco conhecidas, portanto, carentes de informação sobre as fenofases, produção de sementes e de compostos bioativos. Quatro espécies pertencentes à subtribo Hyptidinae (Eplingiella fruticosa (Salzm. ex Benth.) Harley \& J.F.B.Pastore, Mesosphaerum pectinatum (L.) Kuntze, Mesosphaerum suaveolens (L.) Kuntze e Mesosphaerum sidifolium (L'érit.) Harley \& J.F.B.Pastore),, foram selecionadas para esse estudo. Estas, além de produzir compostos bioativos de interesse farmacológico, formam grande quantidade de mucilagem em suas sementes, quando entram em contato com água. As mucilagens são usadas principalmente na indústria alimentícia como espessantes e estabilizadores em uma variedade produtos, incluindo derivados lácteos, sobremesas congeladas, molhos, gomas de mascar e doces (ADA reports, 2005).

Apesar de seu elevado potencial dessas espécies, são escassas informações sobre metodologias de conservação e cultivo. Nesse contexto, estudos fenológicos com o acompanhamento do desenvolvimento das sementes são necessários, buscando identificar o melhor período de colheita, onde as sementes apresentem um maior preenchimento, correlacionando com a produção de mucilagem. Assim, este trabalho objetivou verificar a qualidade das sementes dessas espécies em diferentes estádios de maturação e a quantidade de mucilagem produzida nas condições ambientais de Feira de Santana, Bahia.

\section{MATERIAL E MÉTODOS}

A coleta das sementes será feita de modo ordenado, coletando-se as inflorescências de acordo a coloração do cálice dos racemos na planta, com base na cartela de cores RHS (2001). Para relacionar com os índices de germinação e quantidade de mucilagem extraída,foram identificados quatro estádio de maturação, sendo eles enumerados de 1 a 4, seguindo a coloração para cada estádio, sendo: estádio 1-cálice na cor verde; estádio 2 - cálice na cor verde amarronzado; estádio 3 - cálice na 
cor marrom e estádio 4- cor marrom escuro. Os testes de germinação foram executados em delineamento inteiramente casualizado com quatro repetições de 40 sementes em placas de Petri forradas com papel germitest ${ }^{\circledR}$ duplo embebido com 2,5 vezes seu peso em água destilada e mantidos em câmara de germinação do tipo B.O.D, temperatura alternada $20-30^{\circ} \mathrm{C}$, fotoperíodo de 12 horas. A análise estatística foi realizada por comparação de médias usando o teste Tuckey.

\section{RESULTADOS E DISCUSSÕES}

De acordo com a análise de variância dos resultados de germinação das sementes das espécies Eplingiella fruticosa, Mesosphaerum pectinatum, Mesosphaerum suaveolens e Mesosphaerum sidifolium há diferença significativa quando comparados os estádios de maturação. Os resultados obtidos com as sementes de E.fruticosa (Figura 1) apresentaram diferenças significativas entre os valores de germinação quando comparados os diferentes estádios. O índice de germinação das sementes se mostrou estável para os dois estádios senescente 3 e 4, com diferença significativa, porém, o maior valor de germinação foi 82,5 \% para o estádio 4, Os estádio 1 e 2 não apresentando diferenças significativas quando comparados (Tabela 1). O teor de umidade nas sementes recém colhidas foi de 11,$2 ; 9,3 ; 5,1$ e 4,97\% para os estádios 1 , 2,3 e 4 , respectivamente.

O teor de umidade das sementes recém colhidas foi entre $9,42 \%$ e $4,23 \%$ para os 4 estádios de maturação de $M$. pectinatum. As sementes dessa espécie apresentaram diferenças na taxa de germinação ao longo dos estádios de maturação em comparação (Tabela 2), porém, observou-se uma queda na velocidade de germinação nos estádios 1 e 2, quando as sementes se encontram imaturas. As maiores taxas na germinação foram nos dois últimos estádios.

Figura 01: Estágios de desenvolvimento das inflorescências com base na coloração do
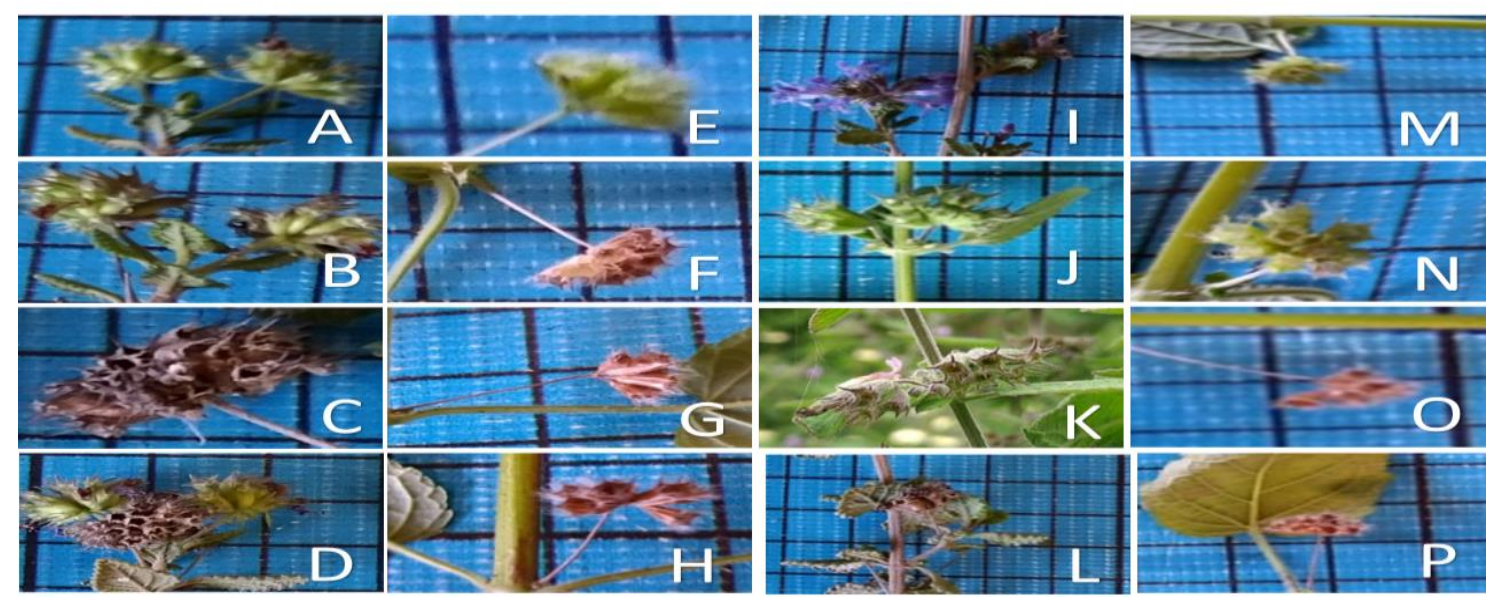

cálice da espécie Eplingiella fruticosa (Salzm. ex Benth.) Harley \& J.F.B.Pastore estádio 1 (A), estádio 2 (B), estádio 3 (C) e estádio 4 (D); Mesosphaerum pectinatum (L.) Kuntze estádio $1(\mathrm{E})$, estádio $2(\mathrm{~F})$, estádio $3(\mathrm{G})$ e estádio $4(\mathrm{H})$; Mesosphaerum suaveolens (L.) Kuntze estádio 1 (I), estádio $2(\mathrm{~J})$, estádio $3(\mathrm{~K})$ e estádio 4 (L); e Mesosphaerum sidifolium (L'érit.) Harley \& J.F.B.Pastore estádio 1 (M), estádio 2 (N), estádio $3(\mathrm{O})$ e estádio $4(\mathrm{P})$. : Cada quadrado corresponde a $1 \mathrm{~cm}^{2}$. Foto: Samuel Silva.

A análise de variância detectou diferenças significativas na interação estádio de maturação x produção de mucilagem para M. suaveolens. Já para o IVG a análise de variância detectou diferenças significativas na comparação dos estádios de maturação, com taxa de germinação de $48,12 \%$ para o estádio 4 e 33,75\% para o estádio 3 (Tabela 2). O teor de umidade ficou entre 14,2 para os estádios iniciais e 3,9 para os estádios de completa maturidade fisiológica. Para $M$. sidifolium detectou-se diferenças 
significativas quando comparados os estádios de maturação e a produção. $\mathrm{O}$ avanço na maturidade fisiológica promoveu um aumento significativo na taxa de germinação e no IVG quando comparados com as avaliações dos estádios iniciais, tanto da germinação quanto da velocidade de germinação (Tabela 4). As sementes colhidas apresentaram $12,2 \%$ e $4,41 \%$ de umidade.

Em contato com água as sementes formaram grande quantidade de mucilagem hialina transparente e de aspecto não fibroso. As espécies que apresentaram os maiores rendimentos foi a $M$. pectinatum e $M$. suaveolens, com rendimento de $8,9 \mathrm{mg}$ de mucilagem para $100 \mathrm{mg}$ de sementes no estádio 4, seguidas por $M$. sidifolium e E.fruticosa com rendimento de $6,8 \mathrm{mg}$ e $6,15 \mathrm{mg}$, respectivamente (Tabela 5).

A mucilagem obtida a partir de sementes de chia pode ser uma nova fonte de polissacarídeos, com o potencial de geração de uma mistura de diferentes polímeros para a produção de filmes e revestimentos com propriedades melhoradas (MUÑOZ et al., 2012). Vázquez-Ovando et al. (2009) exemplificaram que o gel de chia pode ser utilizado na indústria alimentar como estabilizador de espuma, agente de suspensão, emulsificante e agente de ligação. Além disso, pode atuar como substituto de gordura, pois possui a capacidade de hidratar, desenvolver viscosidade e conservar o frescor, especialmente para produtos de panificação. Assim possibilita a utilização dessas espécies na indústria alimentícia.

Tabela 1. Taxa de germinação (G\%), Índice de Velocidade de Germinação (IVG) e Teor de Umidade (TU\%) de sementes de Eplingiella fruticosa (Salzm. ex Benth.) Harley \& J.F.B.Pastore recém colhidas. MG= média geral. Feira de Santana, Bahia. 2018.

\begin{tabular}{llll}
\hline & G\% & IVG & TU\% \\
\hline Estádio 1 & $3.125 \mathrm{c}$ & $0.089 \mathrm{c}$ & 11,2 \\
Estádio 2 & $3.75 \mathrm{c}$ & $0.107 \mathrm{c}$ & 9,3 \\
Estádio 3 & $63.125 \mathrm{~b}$ & $1.8035 \mathrm{~b}$ & 5,1 \\
Estádio 4 & $82.5 \mathrm{a}$ & $2.357 \mathrm{a}$ & 4,97 \\
\hline MG & 38,1250 & 1,0891 & 7,64 \\
\hline
\end{tabular}

As médias seguidas pela mesma letra minúscula na coluna não diferem estatisticamente entre si pelo Teste de Tukey a 5\% de probabilidade de erro.

Tabela 2. Taxa de germinação (G\%), Índice de Velocidade de Germinação (IVG) e Teor de Umidade (TU\%) de sementes de Mesosphaerum pectinatum (L.) Kuntze recém colhidas. $\mathrm{MG}=$ média geral. Feira de Santana, Bahia. 2018.

\begin{tabular}{llll}
\hline & G\% & IVG & TU\% \\
\hline Estádio 1 & $1.25 \mathrm{c}$ & $0.0355 \mathrm{c}$ & 9,42 \\
Estádio 2 & $3.75 \mathrm{c}$ & $0.107 \mathrm{c}$ & 7,23 \\
Estádio 3 & $43.75 \mathrm{~b}$ & $1.25 \mathrm{~b}$ & 5,8 \\
Estádio 4 & $65 \mathrm{a}$ & $1.85725 \mathrm{a}$ & 4,23 \\
\hline MG & 28,4375 & 0,8124 & 6,67 \\
\hline
\end{tabular}

As médias seguidas pela mesma letra minúscula na coluna não diferem estatisticamente entre si pelo Teste de Tukey a 5\% de probabilidade de erro.

Tabela 3. Taxa de germinação (G\%), Índice de Velocidade de Germinação (IVG) e Teor de Umidade (TU) de Mesosphaerum suaveolens (L.) Kuntze recém colhidas. MG= média geral. Feira de Santana, Bahia. 2018.

\begin{tabular}{llll}
\hline & $\mathrm{G} \%$ & IVG & TU \\
\hline Estádio 1 & $0.625 \mathrm{c}$ & $0.01775 \mathrm{c}$ & 14,2 \\
Estádio 2 & $1.875 \mathrm{c}$ & $0.0535 \mathrm{c}$ & 10,1 \\
Estádio 3 & $33.750 \mathrm{~b}$ & $0.96425 \mathrm{~b}$ & 6,01 \\
Estádio 4 & $48.125 \mathrm{a}$ & $1.37525 \mathrm{a}$ & 3,9 \\
\hline MG & 21,094 & 0,6027 & 8,55 \\
\hline
\end{tabular}

As médias seguidas pela mesma letra minúscula na coluna não diferem estatisticamente entre si pelo Teste de Tukey a 5\% de probabilidade de erro. 
Tabela 4. Taxa de germinação (G\%), Índice de Velocidade de Germinação (IVG) e Teor de Umidade (TU) de sementes de Mesosphaerum sidifolium (L'érit.) Harley \& J.F.B.Pastore recém colhidas. MG= média geral. Feira de Santana, Bahia. 2018.

\begin{tabular}{llll}
\hline & $\mathrm{G} \%$ & IVG & TU \\
\hline Estádio 1 & $0.625 \mathrm{c}$ & $0.01775 \mathrm{c}$ & 12,4 \\
Estádio 2 & $1.875 \mathrm{c}$ & $0.21325 \mathrm{c}$ & 9,9 \\
Estádio 3 & $29.375 \mathrm{~b}$ & $0.83925 \mathrm{~b}$ & 6,4 \\
Estádio 4 & $45.625 \mathrm{a}$ & $1.3035 \mathrm{a}$ & 4,41 \\
\hline MG & 19,375 & 0,5934 & 8,27 \\
\hline
\end{tabular}

As médias seguidas pela mesma letra minúscula na coluna não diferem estatisticamente entre si pelo Teste de Tukey a 5\% de probabilidade de erro.

Tabela 5. Produção de mucilagem das sementes de Eplingiella fruticosa (Salzm. ex Benth.) Harley \& J.F.B.Pastore, Mesosphaerum pectinatum (L.) Kuntze, Mesosphaerum suaveolens (L.) Kuntze e Mesosphaerum sidifolium (L'érit.) Harley \& J.F.B.Pastore. Feira de Santana, Bahia. 2018.

\begin{tabular}{c|l|l|l|l}
\hline Espécies & $\begin{array}{l}\text { E. fruticosa } \\
(\mathrm{mg})\end{array}$ & $\begin{array}{l}\text { M. pectinatum } \\
(\mathrm{mg})\end{array}$ & $\begin{array}{l}\text { M. suaveolens } \\
(\mathrm{mg})\end{array}$ & $\begin{array}{l}\text { M. sidifolium } \\
(\mathrm{mg})\end{array}$ \\
\hline $\mathbf{1}$ & $3,175 \mathrm{c}$ & $4,2 \mathrm{~d}$ & $4,05 \mathrm{~d}$ & $2,4 \mathrm{~d}$ \\
$\mathbf{3}$ & $3,175 \mathrm{c}$ & $6 \mathrm{c}$ & $5,7 \mathrm{c}$ & $3,45 \mathrm{c}$ \\
$\mathbf{4}$ & $5,15 \mathrm{~b}$ & $7,75 \mathrm{~b}$ & $7,925 \mathrm{~b}$ & $5,025 \mathrm{~b}$ \\
& $6,15 \mathrm{a}$ & $8,975 \mathrm{a}$ & $8,9 \mathrm{a}$ & $6,8 \mathrm{a}$ \\
& 4,4125 & 6,7312 & 6,6512 & 4,4187
\end{tabular}

As médias seguidas pela mesma letra minúscula na coluna não diferem estatisticamente entre si pelo Teste de Tukey a 5\% de probabilidade de erro.

\section{CONSIDERAÇÕES FINAIS}

Conclui-se, diante dos dados apresentados, o parâmetro visual das inflorescências mostrou-se ser uma alternativa eficiente para determinar o ponto de colheita da semente, garantindo a sua qualidade e uma maior produção de mucilagem.

\section{REFERÊNCIAS}

ADA reports. Position of the American Dietetic Association: Fat Replacers. Journal of the American Dietetic Association, v.105 (2), 266-275, 2005.

BRASIL. Regras para análise de sementes. Ministério da Agricultura, Pecuária e abastecimento, Secretaria de Defesa Agropecuária. Brasília: Mapa/ACS, 2009. 399p.

FELIPPE, G.M.; POLO, M.; CARDOSO, V.J.M.; FIGUEIREDO-RIBEIRO, R.C.L. Germinação da unidade de dispersão da erva invasora Hyptis Suaveolens. Anais, III Seminário Regional de Ecologia. p. 245-261. São Carlos, SP. 1983.

MMA - MINISTÉRIO DO MEIO AMBIENTE. Caatinga. Disponível em: <http://www.mma.gov.br/biomas/caatinga >. Acesso em: 10 mar. 2018.

RHS. THE ROYAL HORTICULTURAL SOCIETY. Colour chart. London: 2001. (4fan). 